\title{
Hyponatremia in a patient with scleroderma renal crisis: a potential role of activated renin-angiotensin system
}

\author{
Hirotaka Fukasawa ${ }^{1 *}$, Ryuichi Furuya ${ }^{1}$, Sayaka Ishigaki ${ }^{1}$, Naoko Kinoshita' ${ }^{1}$, Shinsuke Isobe ${ }^{1}$ and Yoshihide Fujigaki ${ }^{2}$
}

\begin{abstract}
Background: Scleroderma renal crisis is an important complication of scleroderma (systemic sclerosis) that is associated with significant morbidity and mortality. On the other hand, hyponatremia has never been reported in patients with scleroderma renal crisis.

Case presentation: A 66-year-old man with scleroderma was admitted to our hospital for an evaluation of renal dysfunction and extreme hypertension. The laboratory evaluation revealed remarkably high plasma renin activity in association with microangiopathic hemolytic anemia, and the anti-RNA polymerase III antibody assessment was positive. The patient was diagnosed with scleroderma renal crisis and was started treatment with enalapril maleate, an angiotensin-converting enzyme inhibitor. During hospitalization, the patient developed symptomatic hyponatremia three times and each laboratory analysis revealed improperly high levels of antidiuretic hormone without signs of extracellular fluid volume depletion as well as remarkably high plasma renin activities and angiotensin levels. However, hyponatremia has not been demonstrated to occur as a result of combined therapy with candesartan cilexetil, an angiotensin II receptor blocker, and aliskiren fumarate, a direct renin inhibitor. The plasma renin activities and angiotensin levels were normalized and the renal function was maintained after treatment.
\end{abstract}

Conclusions: To our best knowledge, this is the first documented case of scleroderma renal crisis complicated with hyponatremia. This report also suggests that the activated renin-angiotensin system may play a role in the development of hyponatremia and that hyponatremia should be taken into consideration as a rare but possible complication associated with screloderma renal crisis.

Keywords: Hyponatremia, Renin-angiotensin system, Scleroderma renal crisis

\section{Background}

Scleroderma renal crisis (SRC) is an important complication of scleroderma (systemic sclerosis) that is associated with significant morbidity and mortality [1]. Strikingly high levels of plasma renin activity are typically observed accompanying malignant hypertension and it is almost certain that the renin-angiotensin system (RAS) plays a central role in the pathophysiology of SRC. In the late 1970s, angiotensin-converting enzyme (ACE) inhibitors were introduced, and these inhibitors have dramatically improved the outcomes of patients with SRC [2].

\footnotetext{
* Correspondence: hfukasawaucsd@gmail.com

${ }^{1}$ Renal Division, Department of Internal Medicine, Iwata City Hospital, 512-3

Ohkubo, Iwata, Shizuoka 438-8550, Japan

Full list of author information is available at the end of the article
}

Hyponatremia is the most common electrolyte disorder seen in clinical practice [3]. To date, it has been reported that certain ACE inhibitors can cause hyponatremia, although the precise mechanism responsible remains to be elucidated [4].

Here, we report a rare case of SRC complicated with hyponatremia. We also describe the potential relationship between a highly activated RAS and the development of hyponatremia.

\section{Case presentation}

A 66-year-old man with a 10-year history of scleroderma was admitted to our hospital for an evaluation of renal dysfunction and accelerated hypertension in May 2010. His renal function and blood pressure had 
previously been normal. On admission, his blood pressure was $240 / 128 \mathrm{mmHg}$ and he had hypertensive retinopathy with Keith-Wagner grade III fundoscopic changes, sclerodactyly and superficial ulcers of the fingertips. A laboratory evaluation revealed the following: a blood urea nitrogen (BUN) level of $71 \mathrm{mg} / \mathrm{dl}(25.3 \mathrm{mmol} / \mathrm{L})$, a serum creatinine level of $4.69 \mathrm{mg} / \mathrm{dl}(414.6 \mu \mathrm{mol} / \mathrm{L})$ and a plasma renin activity above $20 \mathrm{ng} / \mathrm{ml} / \mathrm{hr}$ (above $5.56 \mathrm{ng} / \mathrm{L} / \mathrm{s}$, normal range $0.9-2.9 \mathrm{ng} / \mathrm{ml} / \mathrm{hr}$ ) with microangiopathic hemolytic anemia. In addition, the anti-RNA polymerase III antibody test was positive, but the anti-Scl-70 (topoisomerase I) antibody test was negative. From these findings, we diagnosed this patient as having SRC and he was immediately treated with the ACE inhibitor, enalapril maleate (Enalapril) at $10 \mathrm{mg} /$ day. After starting the treatment, his blood pressure decreased and renal dysfunction partially improved (Figure 1).

On the $8^{\text {th }}$ day of hospitalization, his consciousness suddenly deteriorated and urgent laboratory findings revealed that his serum sodium level had decreased from $131 \mathrm{mEq} / \mathrm{L}(131 \mathrm{mmol} / \mathrm{L})$ at the time of admission to $116 \mathrm{mEq} / \mathrm{L} \quad(116 \mathrm{mmol} / \mathrm{L})$, his urine osmolarity (332 $\mathrm{mOsm} / \mathrm{kg}=\mathrm{mmol} / \mathrm{kg}$ ) was greater than his serum osmolarity $(261 \mathrm{mOsm} / \mathrm{kg})$ and the level of antidiuretic hormone $(\mathrm{ADH})$ was $6.1 \mathrm{pg} / \mathrm{ml}(5.6 \mathrm{pmol} / \mathrm{L})$, which was

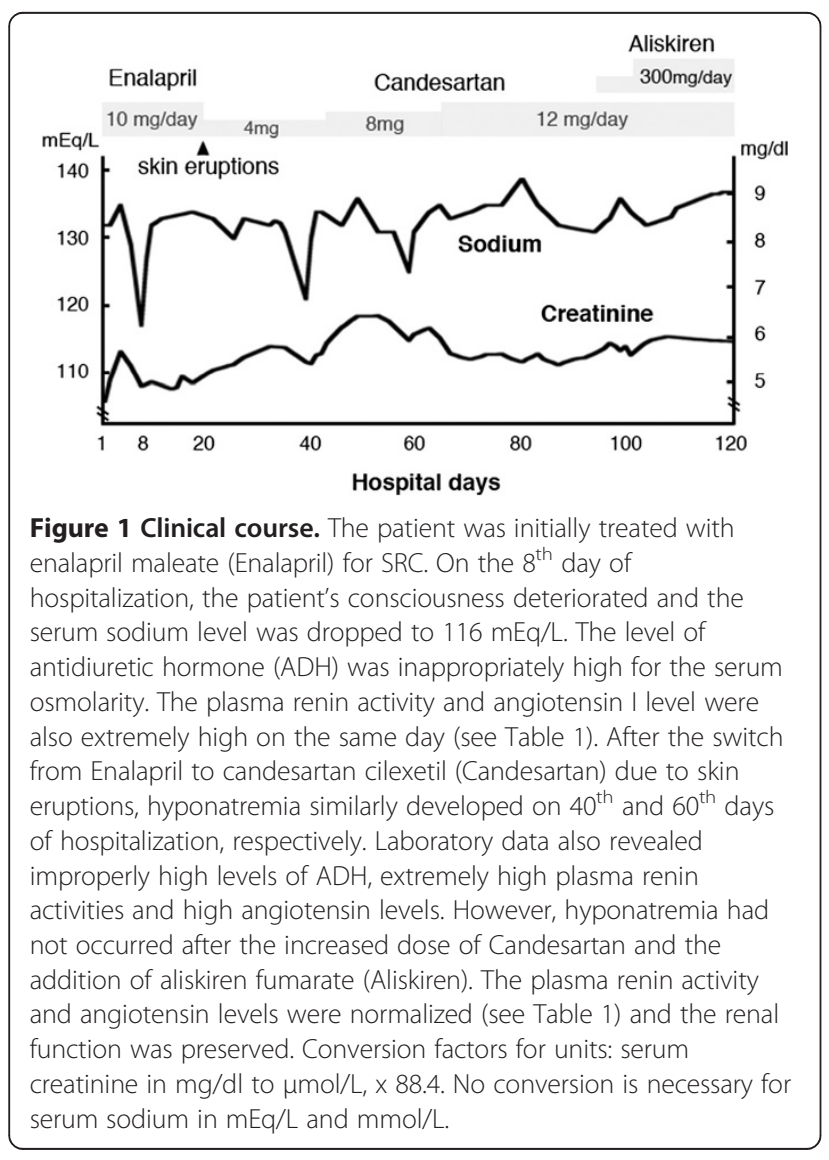

improperly high for the indicated serum osmolarity. His thyroid function was normal and adrenal insufficiency was ruled out. There were no signs of extracellular fluid volume depletion and the results of a brain computed tomography (CT)-scan were normal. Although these data indicated that his hyponatremia was caused via the improper secretion of $\mathrm{ADH}$, the patient did not fulfill the criteria for a diagnosis of the syndrome of inappropriate secretion of ADH (SIADH) due to the coexistence of renal dysfunction. It was also found that the plasma renin activity and angiotensin I levels were extremely high on the $8^{\text {th }}$ day of hospitalization (Table 1). His hyponatremia was treated with water restriction and with the infusion of hypertonic saline.

On the $19^{\text {th }}$ day of hospitalization, he exhibited skin eruptions that were an adverse effect of the Enalapril treatment. Then, Enalapril was replaced with candesar$\tan$ cilexetil (Candesartan) at a dose of $4 \mathrm{mg} /$ day. After this replacement with Candesartan, he developed hyponatremia twice with similar symptoms on the $40^{\text {th }}$ and $60^{\text {th }}$ day of hospitalization, respectively (Figure 1). Laboratory data also revealed improperly high levels of $\mathrm{ADH}$, extremely high plasma renin activity and high angiotensin levels on the $40^{\text {th }}$ and $60^{\text {th }}$ day of hospitalization (Table 1). However, after the dose of Candesartan was increased to $12 \mathrm{mg} /$ day and aliskiren fumarate (Aliskiren) at $300 \mathrm{mg} /$ day was also included in the treatment regimen, his serum sodium levels were normalized and were maintained within the normal range thereafter. His plasma renin activity and angiotensin levels were also normalized and his renal function was preserved.

\section{Conclusions}

Here, we report a rare case of SRC complicated with hyponatremia. To our best knowledge, this is the first case to be described in the literature. Each episode of hyponatremia was accompanied with improperly high levels of $\mathrm{ADH}$, extremely high plasma renin activities and high angiotensin levels without signs of extracellular fluid volume depletion. Furthermore, hyponatremia was prevented via the strong blockade of RAS using a therapeutic combination of the angiotensin II receptor blocker, Candesartan, and the direct renin inhibitor, Aliskiren. Then, it was suggested that the activated RAS might have played an important role in the development of this case of hyponatremia.

To date, there is clear evidence supporting the existence of the central RAS, which is independent of the peripheral RAS [5,6]. Moreover, mechanisms and components required for the formation of angiotensin II have been identified in the brain [6,7]. In accordance with these findings, it has been reported that peripheral angiotensins were unable to penetrate the blood-brain barrier (BBB) 
Table 1 Levels of serum sodium, RAS components and ADH at the time of and after admission

\begin{tabular}{|c|c|c|c|c|c|}
\hline & On admission & Day 8 (1st) & Day 40 (2nd) & Day 60 (3rd) & Day 110 \\
\hline Medication & & Enalapril & Candesartan 4 mg & Candesartan $8 \mathrm{mg}$ & Candesartan 12 mg + Aliskiren \\
\hline Sodium (mEq/L) & 131 & 116 & 120 & 124 & 136 \\
\hline Renin $(0.3-2.9 \mathrm{ng} / \mathrm{ml} / \mathrm{hr})$ & $>20$ & $>20$ & $>20$ & $>20$ & 2.2 \\
\hline Angiotensin I $(<110 \mathrm{pg} / \mathrm{ml})$ & 210 & 1100 & 350 & 560 & $<30$ \\
\hline Angiotensin II (< 22 pg/ml) & 330 & 41 & 1500 & 1100 & 27 \\
\hline Aldosterone (2.9-15.9 ng/dl) & 18.5 & 14.0 & 14.0 & 7.87 & 3.87 \\
\hline $\mathrm{ADH}(\mathrm{pg} / \mathrm{ml})$ & Not determined & 6.1 & 0.9 & 1.0 & Not determined \\
\hline Serum creatinine (mg/dl) & 4.69 & 5.03 & 5.58 & 6.06 & 6.04 \\
\hline Body weight (kg) & Not determined & 49.1 & 46.9 & 48.1 & 46.1 \\
\hline
\end{tabular}

Definition of the abbreviations: RAS, renin-angiotensin system, $\mathrm{ADH}$, antidiuretic hormone, Renin, plasma renin activity. Numerical values in each parenthesis indicate normal values.

Note: Conversion factors for units: plasma renin activity in $\mathrm{ng} / \mathrm{ml} / \mathrm{hr}$ to $\mathrm{ng} / \mathrm{L} / \mathrm{s}, \mathrm{x} 0.2778$; angiotensin I in $\mathrm{pg} / \mathrm{ml}$ to $\mathrm{fmol} / \mathrm{ml}, \mathrm{x} 0.772$; angiotensin II in pg/ml to $\mathrm{fmol} / \mathrm{ml}, \mathrm{x}$ 0.956; aldosterone in $\mathrm{ng} / \mathrm{dl}$ to $\mathrm{nmol} / \mathrm{L}, \times 0.02774 ; \mathrm{ADH}$ in $\mathrm{pg} / \mathrm{ml}$ to $\mathrm{pmol} / \mathrm{L}, \times 0.923$; serum $\mathrm{creatinine}$ in $\mathrm{mg} / \mathrm{dl}$ to $\mathrm{mmol} / \mathrm{L}, \mathrm{x} 88.4$. No conversion is necessary for serum sodium in $\mathrm{mEq} / \mathrm{L}$ and $\mathrm{mmol} / \mathrm{L}$.

under normal physiological conditions [8]. It has also been reported that Enalapril [9], Candesartan [8] and Aliskiren (unpublished data by Novartis Pharmaceuticals Corporation) were unable to penetrate the BBB.

On the other hand, it has been reported that high levels of angiotensin II in the peripheral circulation (for example, via the infusion of angiotensin II) could affect the central actions including the secretion of $\mathrm{ADH}$ [10]. The effects of high levels of angiotensin II on the hypothalamic-neurohypophysial system are mediated via circumventricular organs (CVOs), such as the subfornical organ and the organum vasculosum of the lamina terminalis. These organs anatomically lack the BBB, and as a result, angiotensins in the peripheral circulation are accessible to these sites [11]. Accordingly, it is likely that supra-physiological levels of angiotensin II were involved in the improper secretion of $\mathrm{ADH}$ resulting from the anatomical characteristics of CVOs and these factors subsequently led the development of hyponatremia in our case (Figure 2).

Circulating angiotensin I is converted into angiotensin II by ACE mainly in the lungs, and ACE inhibitors can block this conversion process. In fact, the level of angiotensin I, but not angiotensin II, was remarkably high at the time when the first episode of hyponatremia developed on the $8^{\text {th }}$ day of hospitalization, because the patient was treated with Enalapril, an ACE inhibitor (Table 1). Interestingly, much higher ACE activities have been identified in CVOs compared to those in lungs [12] and Thunhorst et al. [13] showed that the peripheral ACE blockade with anti-hypertensive doses could not inhibit the ACE activities in CVOs. Therefore, it was possible that the remarkably high levels of angiotensin I reached in CVOs were locally converted into angiotensin II, that the converted (and likely high levels of) angiotensin II stimulated $\mathrm{ADH}$ secretion, and that the first episode of hyponatremia finally developed on the $8^{\text {th }}$ day of hospitalization.

However, we cannot exclude the following alternative possibilities: (i) that the disturbance of free water excretion due to renal dysfunction co-existed also played a role in the development of hyponatremia and (ii) that the permeability of the BBB for angiotensins was altered due to the pathological condition of SRC.

In conclusion, we experienced this rare case of SRC complicated with hyponatremia. Further studies are required to clarify the precise mechanism responsible for the association between SRC and hyponatremia,

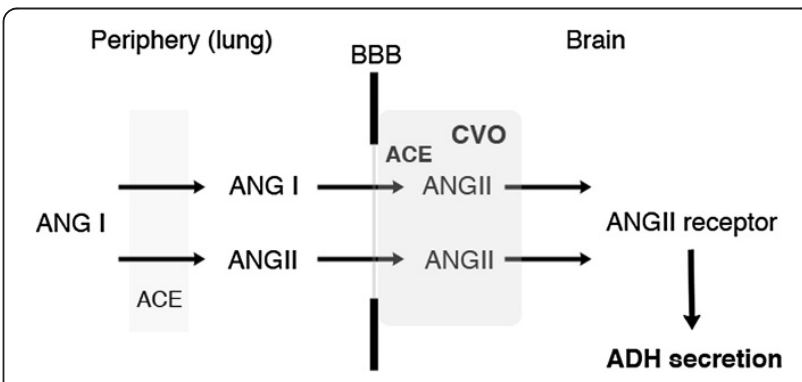

Figure 2 Diagram of the potential relationship between peripheral and central renin-angiotensin systems and $\mathrm{ADH}$ secretion. Angiotensin II (ANGII) in the peripheral circulation is accessible to circumventricular organs (CVOs), which lack the bloodbrain barrier (BBB). Within CVOs, high levels of ANGII (for example, via the infusion of ANGII) can stimulate the ADH secretion via ANGII receptors in the brain. Most of the blood-borne angiotensin I (ANG I) is converted into ANGII at the lungs by the angiotensin-converting enzyme (ACE) under physiological conditions, although the rate of this conversion process is decreased under pathological conditions. Because the activity of ACE in CVOs is much higher than that in the lungs, the redundant ANG I may be converted to ANGIl locally and this converted (and high levels of) ANGII may then stimulate the ADH secretion. 
although the activated RAS may play an important role in the development of hyponatremia in this case.

\section{Consent}

Written informed consent was obtained from the patient for publication of this Case report and any accompanying images. A copy of the written consent is available for review by the Series Editor of this journal.

\section{Abbreviations}

ACE: Angiotensin converting enzyme; ADH: Antidiuretic hormone; BBB: Blood-brain barrier; BUN: Blood urea nitrogen; CT: Computed tomography; CVO: Circumventricular organ; RAS: Renin-angiotensin system; SIADH: Syndrome of inappropriate of ADH secretion; SRC: Scleroderma renal crisis.

\section{Competing interests}

'The authors declare that they have no competing interests.

\section{Authors' contributions}

HF, Sal, NK and Shl treated the patient. HF wrote the first draft and also evaluated the data. RF and YF wrote the final draft. All authors reviewed the final version of this manuscript.

\section{Acknowledgements}

None

\section{Author details}

'Renal Division, Department of Internal Medicine, Iwata City Hospital, 512-3 Ohkubo, Iwata, Shizuoka 438-8550, Japan. ${ }^{2}$ First Department of Medicine, Hamamatsu University School of Medicine, 1-20-1 Handayama, Higashi-ku, Hamamatsu, Shizuoka 431-3192, Japan.

Received: 2 January 2012 Accepted: 27 June 2012

Published: 27 June 2012

\section{References}

1. Traub YM, Shapiro AP, Rodnan GP, Medsger TA, McDonald RH Jr, Steen VD, Osial TA Jr, Tolchin SF: Hypertension and renal failure (scleroderma renal crisis) in progressive systemic sclerosis. Review of a 25-year experience with 68 cases. Medicine (Baltimore) 1983, 62:335-352.

2. Lopez-Ovejero JA, Saal SD, D'Angelo WA, Cheigh JS, Stenzel KH, Laragh JH: Reversal of vascular and renal crises of scleroderma by oral angiotensinconverting-enzyme blockade. N Engl J Med 1979, 300:1417-1419.

3. Anderson RJ, Chung HM, Kluge R, Schrier RW: Hyponatremia: a prospective analysis of its epidemiology and the pathogenetic role of vasopressin. Ann Intern Med 1985, 102:164-168.

4. Izzedine H, Fardet L, Launay-Vacher V, Dorent R, Petitclerc T, Deray G: Angiotensin-converting enzyme inhibitor-induced syndrome of inappropriate secretion of antidiuretic hormone: case report and review of the literature. Clin Pharmacol Ther 2002, 71:503-507.

5. Wright JW, Harding JW: Regulatory role of brain angiotensins in the control of physiological and behavioral responses. Brain Res Rev 1992, 17:227-262.

6. Bader M, Peters J, Baltatu O, Muller DN, Luft FC, Ganten D: Tissue reninangiotensin systems: new insights from experimental animal models in hypertension research. J Mol Med (Berl) 2001, 79:76-102.

7. Ganong WF: Origin of the angiotensin II secreted by cells. Proc Soc Exp Biol Med 1994, 205:213-219.

8. Pelisch N, Hosomi N, Ueno M, Masugata H, Murao K, Hitomi H, Nakano D, Kobori H, Nishiyama A, Kohno M: Systemic candesartan reduces brain angiotensin II via downregulation of brain renin-angiotensin system. Hypertens Res 2010, 33:161-164.

9. Sink KM, Leng X, Williamson J, Kritchevsky SB, Yaffe K, Kuller L, Yasar S, Atkinson H, Robbins M, Psaty B, Goff DC Jr: Angiotensin-converting enzyme inhibitors and cognitive decline in older adults with hypertension: results from the Cardiovascular Health Study. Arch Intern Med 2009, 169:1195-1202.

10. Fitzsimons JT: Angiotensin, thirst, and sodium appetite. Physiol Rev 1998, 78:583-686.
11. Thrasher TN, Keil LC: Regulation of drinking and vasopressin secretion: role of organum vasculosum laminae terminalis. Am J Physiol 1987, 253: R108-R120.

12. Chevillard C, Saavedra JM: Distribution of angiotensin-converting enzyme activity in specific areas of the rat brain stem. J Neurochem 1982, 38:281-284.

13. Thunhorst RL, Fitts DA, Simpson JB: Angiotensin-converting enzyme in subfornical organ mediates captopril-induced drinking. Behav Neurosci 1989, 103:1302-1310.

doi:10.1186/1471-2369-13-47

Cite this article as: Fukasawa et al: Hyponatremia in a patient with scleroderma renal crisis: a potential role of activated renin-angiotensin system. BMC Nephrology 2012 13:47.

\section{Submit your next manuscript to BioMed Central and take full advantage of:}

- Convenient online submission

- Thorough peer review

- No space constraints or color figure charges

- Immediate publication on acceptance

- Inclusion in PubMed, CAS, Scopus and Google Scholar

- Research which is freely available for redistribution 